\title{
Prevalence of Toxoplasma gondii and Associated Risk Factors among People Living with HIV at Gondar University Hospital, Northwest Ethiopia
}

\author{
Dagnachew Muluye, ${ }^{1}$ Yitayih Wondimeneh, ${ }^{2}$ Yeshambel Belyhun, ${ }^{1,3}$ Feleke Moges, \\ Mengistu Endris, ${ }^{1}$ Getachew Ferede, ${ }^{2}$ Gashaw Yitayew, ${ }^{1}$ and Digsu Negese ${ }^{4}$ \\ ${ }^{1}$ Department of Medical Microbiology, School of Biomedical and Laboratory Sciences, College of Medicine and Health Sciences, \\ University of Gondar, P.O. Box 196, Gondar, Ethiopia \\ ${ }^{2}$ Department of Medical Parasitology, School of Biomedical and Laboratory Sciences, College of Medicine and Health Sciences, \\ University of Gondar, P.O. Box 196, Gondar, Ethiopia \\ ${ }^{3}$ Institute of Virology, Faculty of Medicine, University of Leipzig, Johannisallee 30, 04103 Leipzig, Germany \\ ${ }^{4}$ Department of Epidemiology and Biostatistics, Institute of Public Health, College of Medicine and Health Sciences, \\ University of Gondar, P.O. Box 196, Gondar, Ethiopia
}

Correspondence should be addressed to Dagnachew Muluye; dagne24@gmail.com

Received 18 June 2013; Accepted 10 July 2013

Academic Editors: R. Dey, R. E. Fretes, S. P. Lim, and S. Munga

Copyright (C) 2013 Dagnachew Muluye et al. This is an open access article distributed under the Creative Commons Attribution License, which permits unrestricted use, distribution, and reproduction in any medium, provided the original work is properly cited.

Background. Toxoplasma gondii is an obligate intracellular protozoan parasite and is a major opportunistic pathogen in immunecompromised hosts. This study assessed the prevalence of $T$. gondii and associated risk factors among people living with HIV. Methods and Materials. A cross-sectional study was carried out among people living with HIV attending Gondar University Hospital. A structured and pretested questionnaire was used to collect sociodemographic factors, and $10 \mathrm{~mL}$ of venous blood was collected for anti-Toxoplasma antibody test and determination of CD4 levels. Serum was tested in duplicate for anti-Toxoplasma antibody using rapid slide agglutination test. Results. A total of 170 study subjects were enrolled in the study. Seroprevalence of T. gondii among the study participants was $76.5 \%$ (95\% CI: 69.0-82.8). High proportions of seropositive individuals (64.7\%) were found under the child bearing age groups. The mean CD4+ lymphocyte count of HIV monoinfected participants was $495.7 \pm 334$ cells $/ \mathrm{mm}^{3}$ while coinfected study participants had mean CD4+ lymphocyte count of $403.5 \pm 218.7 \mathrm{cells} / \mathrm{mm}^{3}$ with $P$ value of 0.01 . Conclusion. The seroprevalence of T. gondii among people living with HIV was high. Cautious followup of HIV-positive patients is needed to prevent development of toxoplasmic encephalitis and other related complications.

\section{Introduction}

Toxoplasma gondii is an obligate intracellular protozoan of worldwide distribution and is a major opportunistic pathogen in immunocompromised hosts. Infection is mainly acquired by ingestion of food, water or soil that is contaminated with oocysts shed by cats or by eating undercooked or raw meat containing tissue cysts [1].

Toxoplasmosis in patients with AIDS is usually the result of reactivation of latent infection. In HIV-positive people, without previous exposure to $T$. gondii, the acute infection could not be well controlled and in these susceptible hosts a wide range of infections is expected [2]. Toxoplasmosis occurs mostly in brain that is the frequent clinical finding [3, 4] even in patients with latent toxoplasmosis. Seroprevalence varies greatly in geographical regions within a country and within different ethnic groups according to different environments, social customs, and habits of different populations $[5,6]$.

There is wide geographic variation in the prevalence of latent Toxoplasma infection. Studies from Latin America, Europe, Asia, and Africa have reported a range of prevalence estimates of $30 \%-75 \%$ and prevalence estimates from US studies have had a range of $3 \%-42 \%$ [7, 8]. Worldwide 
prevalence rate of latent Toxoplasma infections in HIVinfected patients including Ethiopia has been found to vary greatly from $3 \%$ to $97 \%[9,10]$.

It is usually subacute in onset with focal neurologic signs frequently accompanied by fever, altered mental state, and headache. Cerebellar, subcortical, or cortical lesions can be present in over $50 \%$ of the infected cases, resulting in hemiparesis, ambulatory, and gait or speech abnormalities [11]. A significant proportion of encephalitic patients can also present with neuropsychiatric disorders including psychosis, dementia, anxiety, and personality disorder [12]. However, despite the recognized public health importance of $T$. gondii in different parts of the world, studies on the prevalence of toxoplasmosis among people living with HIV are scanty in Ethiopia and unavailable in the study area.

Despite complications of HIV/AIDS patients due to rampant opportunistic infections, reports on the magnitude of $T$. gondii in such population groups are very minimal. The epidemiology of toxoplasmosis in HIV/AIDS patients should be able to provide us with a better understanding of the clinical scenario. Therefore, the present study assessed the prevalence of T. gondii and associated factors among people living with HIV.

\section{Methods}

2.1. Study Design, Area, and Period. An institution-based cross-sectional study was carried out among people living with HIV from November 2012 to February 2013 at Gondar University Hospital, Northwest Ethiopia.

2.2. Study Population and Sampling Procedures. The source populations for this study were all HIV-positive patients attending Gondar University Hospital. A single population proportion formula was used to estimate sample size. The following assumptions have been made: 95\% confidence interval, 93\% proportion of T. gondii seropositivity among HIV-positive individuals [9], 4\% margin of error, and $10 \%$ expected nonresponse rate. As a result a total of 170 study subjects were enrolled in the study. Systematic random sampling technique was used to select study participants.

2.3. Data Collection Procedures. Interview using structured and pretested questionnaire was performed to investigate risk factors associated with $T$. gondii infection, including consumption of raw meat and keeping pets (cats and dogs), and to collect data on sociodemographic characteristics of study subject. Ten milliliter $(10 \mathrm{~mL})$ of venous blood was aseptically collected for the determination of $T$. gondii seroprevalence and CD4+ levels from each study participant. The CD4+ levels were determined by using BD FACS count flow cytometry [13]. Sera were tested in duplicate for antiToxoplasma antibody using Toxo Latex manufactured by Linear chemicals S.L, Barcellona, Spain, with a sensitivity of $92 \%$ and specificity of $95 \%$. Positive and negative controls were included per each batch of test run to ensure that reagents are working properly, and technical procedures are carried out correctly.
2.4. Data Analysis Procedure. Data were entered and analyzed using SPSS version 20 statistical package. The association between selected variables and seropositivity was analyzed using Chi-square test and $t$-test was used to see the association between mean CD4+ values and seropositivity. $P$ value $\leq 0.05$ was considered as significant.

2.5. Ethical Considerations. Ethical clearance was obtained from Ethical Review Board of University of Gondar, College of Medicine and Health Sciences. Informed and written consent was obtained from each study participant prior to data collection and all results were kept confidential.

\section{Results}

3.1. Sociodemographic Characteristics. A total of 170 study subjects were enrolled in the study. Out of these, $96(56.5 \%)$ were females. The mean age of study participants was $33.34 \pm$ 12.34 years. The majority of study participants (91.2\%) were from urban residents. More than $89 \%$ of the participants were orthodox religion followers and $43.5 \%$ were married. Out of the total study participants, $42(24.7 \%)$ were governmental employees followed by daily laborers (21.2\%) and housewives $(21.1 \%)$. More than one-third of study participants were secondary school and above in educational status (Table 1).

3.2. Prevalence of $T$. gondii. Seroprevalence of $T$. gondii among study participants was 130/170 (76.5\%) (95\% CI: 69.082.8). Among seropositive study participants, 71 (54.6\%) were females. More than $38 \%$ of seropositive individuals were under the age group of 31-40 years followed by $18-30$ years $(26.2 \%)$. All farmers were found to be infected by $T$. gondii. Of all study participants, 137 (80.6\%) were on ART while $19.4 \%$ were pre-ART and $80 \%$ of seropositive study participants were on ART. Among 27 study participants who had contact with dog, $22(81.5 \%)$ were seropositive for $T$. gondii. Of 45 study participants who had contact with cats, $35(77.8 \%)$ were seropositive for T. gondii. More than $30 \%$ of study participants had frequent experience of raw meat consumption. Of these, $76.9 \%$ were seropositive for T. gondii. Seventy-nine $(60.8 \%)$ of seropositive study participants had CD $4+$ lymphocyte count of $\geq 350$ cells $/ \mathrm{mm}^{3}$. The mean CD4+ lymphocyte count of HIV monoinfected participants was $495.7 \pm 334$ cells $/ \mathrm{mm}^{3}$, and $T$. gondii seropositive study participants had mean CD4+ lymphocyte count of $403.5 \pm$ 218.7 cells $/ \mathrm{mm}^{3}$ with $P$ value of 0.01 (Table 2). Statistical analysis was performed to see the association between variables suspected as risk factors and seroprevalence of $T$. gondii; meanwhile all the variables did not show statistically significant association.

\section{Discussion}

Worldwide prevalence rate of latent Toxoplasma infections in HIV-infected patients including Ethiopia has been found to vary greatly from $3 \%$ to $97 \%[9,10]$. In this study, $76.5 \%$ of study participants were seropositive for $T$. gondii. This result was lower than study findings of Addis Ababa, Ethiopia 
TABLE 1: Sociodemographic characteristics of study participants at Gondar University Hospital from November 2012 to April 2013.

\begin{tabular}{|c|c|c|}
\hline Characteristics & Number $(n=170)$ & Percent (\%) \\
\hline \multicolumn{3}{|l|}{ Age of the respondents } \\
\hline$<18$ & 20 & 11.8 \\
\hline $18-30$ & 48 & 28.2 \\
\hline $31-40$ & 61 & 35.9 \\
\hline $41-50$ & 32 & 18.8 \\
\hline$>50$ & 9 & 5.3 \\
\hline \multicolumn{3}{|l|}{ Sex } \\
\hline Female & 96 & 56.5 \\
\hline Male & 74 & 43.5 \\
\hline \multicolumn{3}{|l|}{ Residency } \\
\hline Urban & 155 & 91.2 \\
\hline Rural & 15 & 8.8 \\
\hline \multicolumn{3}{|l|}{ Religion } \\
\hline Orthodox & 152 & 89.4 \\
\hline Muslim & 16 & 9.4 \\
\hline Protestant & 2 & 1.2 \\
\hline \multicolumn{3}{|l|}{ Marital status } \\
\hline Single & 39 & 22.9 \\
\hline Married & 74 & 43.5 \\
\hline Divorced & 33 & 19.4 \\
\hline Windowed & 24 & 14.1 \\
\hline \multicolumn{3}{|l|}{ Educational status } \\
\hline No formal education & 50 & 29.4 \\
\hline Primary education & 58 & 34.1 \\
\hline Secondary and above & 62 & 36.5 \\
\hline \multicolumn{3}{|l|}{ Occupation } \\
\hline Government employee & 42 & 24.7 \\
\hline Housewife & 36 & 21.2 \\
\hline Student & 19 & 11.2 \\
\hline Merchant & 22 & 12.9 \\
\hline Daily laborer & 36 & 21.2 \\
\hline Farmer & 10 & 5.9 \\
\hline Others & 5 & 2.9 \\
\hline
\end{tabular}

(93.3\%) [9]. The lower result in our study could be due to the diagnostic method used. In contrast, this result was higher than findings in Iran (38.01\%) and Malaysia (44.8\%) $[14,15]$. The difference might be due to the sociocultural differences in keeping dogs and cats at home. Moreover, consumption of raw and insufficiently cooked meat consumption is higher in Ethiopia which is supposed to be a risk factor for T. gondii infection.

In this study, more than two-thirds of study participants had cats and/or dogs at their home. Unpredictably, ownership of cats and/or dogs, age, and sex were not statistically significant with seroprevalence of T. gondii. This could be due to the small sample size we used as well as the mass coverage of supposed factors irrespective of age and sex. In addition, a study conducted in South Africa, with the same sample size of study participants, showed lower (18.1\%) prevalence compared to the current study [16]. Age and sex were not
TABLE 2: Seroprevalence of Toxoplasma gondii among study participants at Gondar University Hospital from November 2012 to April 2013.

\begin{tabular}{|c|c|c|}
\hline \multirow{2}{*}{ Characteristics } & \multicolumn{2}{|c|}{ T. gondii } \\
\hline & Positive (\%) & Negative (\%) \\
\hline \multicolumn{3}{|l|}{ Age of the respondents } \\
\hline$<18$ & $15(11.5)$ & $5(12.5)$ \\
\hline $18-30$ & $34(26.2)$ & $14(35.0)$ \\
\hline $31-40$ & $50(38.5)$ & $11(27.5)$ \\
\hline $41-50$ & $23(17.7)$ & $9(22.5)$ \\
\hline$>50$ & $8(6.2)$ & $1(2.5)$ \\
\hline \multicolumn{3}{|l|}{ Sex } \\
\hline Female & $71(54.6)$ & $25(62.5)$ \\
\hline Male & $59(45.4)$ & $15(37.5)$ \\
\hline \multicolumn{3}{|l|}{ Residency } \\
\hline Urban & $119(91.5)$ & $36(90.0)$ \\
\hline Rural & $11(8.5)$ & $4(10.0)$ \\
\hline \multicolumn{3}{|l|}{ Religion } \\
\hline Orthodox & $115(88.5)$ & $37(92.5)$ \\
\hline Muslim & $13(10.0)$ & $3(7.5)$ \\
\hline Protestant & $2(1.5)$ & $0(0.0)$ \\
\hline \multicolumn{3}{|l|}{ Marital status } \\
\hline Single & $28(21.5)$ & $11(27.5)$ \\
\hline Married & $55(42.3)$ & $19(47.5)$ \\
\hline Divorced & $26(20.0)$ & $7(17.5)$ \\
\hline Window & $21(16.2)$ & $3(7.5)$ \\
\hline \multicolumn{3}{|l|}{ Educational status } \\
\hline Illiterate & $41(31.5)$ & $9(22.5)$ \\
\hline Primary education & $42(32.3)$ & $16(40.0)$ \\
\hline Secondary and above & $47(36.2)$ & $15(37.5)$ \\
\hline \multicolumn{3}{|l|}{ Occupation } \\
\hline Govt. employee & $33(25.4)$ & $9(22.5)$ \\
\hline Housewife & $24(18.5)$ & $12(30.0)$ \\
\hline Student & $13(10)$ & $6(15.0)$ \\
\hline Merchant & $16(12.3)$ & $6(15.0)$ \\
\hline Daily laborer & $30(23.1)$ & $6(15.0)$ \\
\hline Farmer & $10(7.7)$ & $0(0.0)$ \\
\hline Other & $4(3.1)$ & $1(2.5)$ \\
\hline \multicolumn{3}{|l|}{ ART } \\
\hline Pre-ART & $26(20.0)$ & $7(17.5)$ \\
\hline On ART & $104(80.0)$ & $33(82.5)$ \\
\hline \multicolumn{3}{|l|}{ CD4+ lymphocyte count } \\
\hline$<200$ cells $/ \mathrm{mm}^{3}$ & $23(17.7)$ & $4(10.0)$ \\
\hline $200-349$ cells $/ \mathrm{mm}^{3}$ & $28(21.5)$ & $12(30.0)$ \\
\hline$\geq 350$ cells $/ \mathrm{mm}^{3}$ & $79(60.8)$ & $24(60.0)$ \\
\hline \multicolumn{3}{|c|}{ Do you have contact with the cat? } \\
\hline Yes & $35(26.9)$ & $10(25.0)$ \\
\hline No & $95(73.1)$ & $30(75.0)$ \\
\hline \multicolumn{3}{|c|}{ Do you have contact with the dog? } \\
\hline Yes & $22(16.9)$ & $5(12.5)$ \\
\hline No & $108(83.1)$ & $35(87.5)$ \\
\hline
\end{tabular}


TABLE 2: Continued.

\begin{tabular}{lcc}
\hline \multirow{2}{*}{ Characteristics } & \multicolumn{2}{c}{ T. gondii } \\
& Positive (\%) & Negative (\%) \\
\hline Source of water for drinking & $123(94.6)$ & $38(95.0)$ \\
$\quad$ Pipe water & $3(2.3)$ & $2(5.0)$ \\
$\quad$ River & $3(2.3)$ & $0(0.0)$ \\
Well & $1(0.8)$ & $0(0.0)$ \\
Other & & \\
Do you boil the water before drinking & $5(3.8)$ & $4(10.0)$ \\
$\quad$ Yes & $125(96.2)$ & $36(90.0)$ \\
$\quad$ No & & \\
Raw meat consumption & $40(30.8)$ & $12(30.0)$ \\
$\quad$ Yes & $90(69.2)$ & $28(70.0)$ \\
$\quad$ No &
\end{tabular}

statistically significant which is in agreement with our study. All farmers were seropositive in this study which is supported by previously recognized risk factors which are common among farmers.

The majority of seropositive individuals (64.7\%) were found under the child bearing age groups (18-40 year) which was also reported in other studies [14, 17]. This might cause congenital anomalies for newborns born from infected mothers not only HIV-positive mothers but also among the general population.

The mean CD4+ lymphocyte count of HIV monoinfected participants was $495.7 \pm 334$ cells $/ \mathrm{mm}^{3}$ while $T$. gondii seropositive study participants had mean CD4+ lymphocyte count of $403.5 \pm 218.7 \mathrm{cells} / \mathrm{mm}^{3}$ with $P$ value of 0.01 . However, it is difficult to explain the effect of CD4+ lymphocyte count level on T. gondii infection as recent or remote infection is not determined. The largest proportion (60.8\%) of seropositive study participants had CD4+ lymphocyte count of $\geq 350$ cells $/ \mathrm{mm}^{3}$. Risk of development of toxoplasmic encephalitis for AIDS patients who were seropositive for $T$. gondii is higher within two years after the onset of AIDS, while toxoplasmic encephalitis occurs rarely in AIDS patients who were seronegative for the parasite during pre-AIDS stage [18]. In this study, rapid slide agglutination test was used to detect anti-Toxoplasma antibody, hence it is the limitation of the study.

\section{Conclusion}

The seroprevalence of T. gondii among people living with HIV was high. Cautious followup of HIV-positive individuals is needed to prevent development of toxoplasmic encephalitis and other related complications as studies confirmed that $T$. gondii infection was high among people living with HIV.

\section{Conflict of Interests}

The authors declare that they have no conflict of interests.

\section{Acknowledgments}

The authors acknowledge the technical support provided by University of Gondar. Their special thanks and appreciation go to all the study participants who voluntarily participated in this study. We also thank Gondar University hospital ART laboratory personnel for their support during data collection.

\section{References}

[1] R. Fayer, J. P. Dubey, and D. S. Lindsay, "Zoonotic protozoa: from land to sea," Trends in Parasitology, vol. 20, no. 11, pp. 531536, 2004.

[2] B. G. Gellin and R. Soave, "Coccidian infections in AIDS: toxoplasmosis, cryptosporidiosis, and isosporiasis," Medical Clinics of North America, vol. 76, no. 1, pp. 205-234, 1992.

[3] C. Contini, "Clinical and diagnostic management of toxoplasmosis in the immunocompromised patient," Parassitologia, vol. 50, no. 1-2, pp. 45-50, 2008.

[4] J. E. Vidal, A. V. Hernandez, A. C. Penalva de Oliveira, R. F. Dauar, S. P. Barbosa Jr., and R. Focaccia, "Cerebral toxoplasmosis in HIV-positive patients in Brazil: clinical features and predictors of treatment response in the HAART era," AIDS Patient Care and STDs, vol. 19, no. 10, pp. 626-634, 2005.

[5] P. A. Conrad, M. A. Miller, C. Kreuder et al., "Transmission of Toxoplasma: clues from the study of sea otters as sentinels of Toxoplasma gondii flow into the marine environment," International Journal for Parasitology, vol. 35, no. 11-12, pp. 11551168, 2005.

[6] B. T. E. Chan, R. N. Amal, M. I. Noor Hayati et al., "Seroprevalence of toxoplasmosis among migrant workers from different Asian countries working in Malaysia," Southeast Asian Journal of Tropical Medicine and Public Health, vol. 39, no. 1, pp. 9-13, 2008.

[7] J. Zufferey, A. Sugar, P. Rudaz, J. Bille, M. P. Glauser, and J. P. Chave, "Prevalence of latent toxoplasmosis and serological diagnosis of active infection in HIV-Positive patients," European Journal of Clinical Microbiology and Infectious Diseases, vol. 12, no. 8, pp. 591-595, 1993.

[8] B. J. Luft and J. S. Remington, “Toxoplasmic encephalitis," Journal of Infectious Diseases, vol. 157, no. 1, pp. 1-6, 1988.

[9] T. Shimelis, M. Tebeje, E. Tadesse, B. Tegbaru, and A. Terefe, "Sero-prevalence of latent Toxoplasma gondii infection among HIV-infected and HIV-uninfected people in Addis Ababa, Ethiopia: a comparative cross-sectional study," BMC Research Notes, vol. 2, article 213, 2009.

[10] V. Nissapatorn, "Toxoplasmosis in HIV/AIDS: a living legacy," Southeast Asian Journal of Tropical Medicine and Public Health, vol. 40, no. 6, pp. 1158-1178, 2009.

[11] B. J. Luft, R. Hafner, A. H. Korzun et al., "Toxoplasmic encephalitis in patients with the acquired immunodeficiency syndrome. Members of the ACTG 077p/ANRS 009 Study Team," The New England Journal of Medicine, vol. 329, pp. 995-1000, 1993.

[12] E. F. Torrey and R. H. Yolken, “Toxoplasma gondii and Schizophrenia," Emerging Infectious Diseases, vol. 9, no. 11, pp. 1375$1380,2003$.

[13] "BD FACS Count System User's Guide for Use with BD FACS Count CD4 Reagents," 2008, http://www.bdbiosciences.com/ external_files/pm/doc/manuals/live/web_enabled/339011. 
[14] R. Shafiei, Z. Riazi, M. Sarvghad, M. G. Sharifdini, A. Mahmoodzadeh, and M. Hajia, "Prevalence of IgG and IgM antiToxoplasma gondii antibodies in HIV positive patients in northeast of Iran," Iranian Journal of Pathology, vol. 6, no. 2, pp. 68-72, 2011.

[15] V. Nissapatorn, C. Lee, K. F. Quek, C. L. Leong, R. Mahmud, and K. A. Abdullah, "Toxoplasmosis in HIV/AIDS patients: a current situation," Japanese Journal of Infectious Diseases, vol. 57, no. 4, pp. 160-165, 2004.

[16] P. O. Bessong and L. M. Mathomu, "Seroprevalence of HTLV1/2, HSV1/2 and Toxoplasma gondii among chronic HIV-1 infected individuals in rural northeastern South Africa," African Journal of Microbiology Research, vol. 4, no. 23, pp. 2587-2591, 2010.

[17] A. Pauwels, M. C. Meyohas, M. Eliaszewicz, C. Legendre, G. Mougeot, and J. Frottier, "Toxoplasma colitis in the acquired immunodeficiency syndrome," American Journal of Gastroenterology, vol. 87, no. 4, pp. 518-519, 1992.

[18] M. A. Abu-Madi, N. Al-Molawi, and J. M. Behnke, "Seroprevalence and epidemiological correlates of Toxoplasma gondii infections among patients referred for hospital-based serological testing in Doha, Qatar," Parasites and Vectors, vol. 1, no. 1, article 39, 2008. 


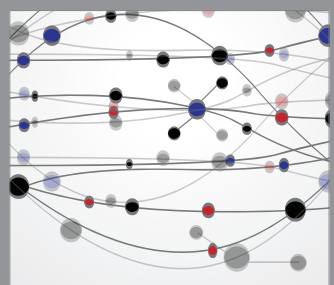

The Scientific World Journal
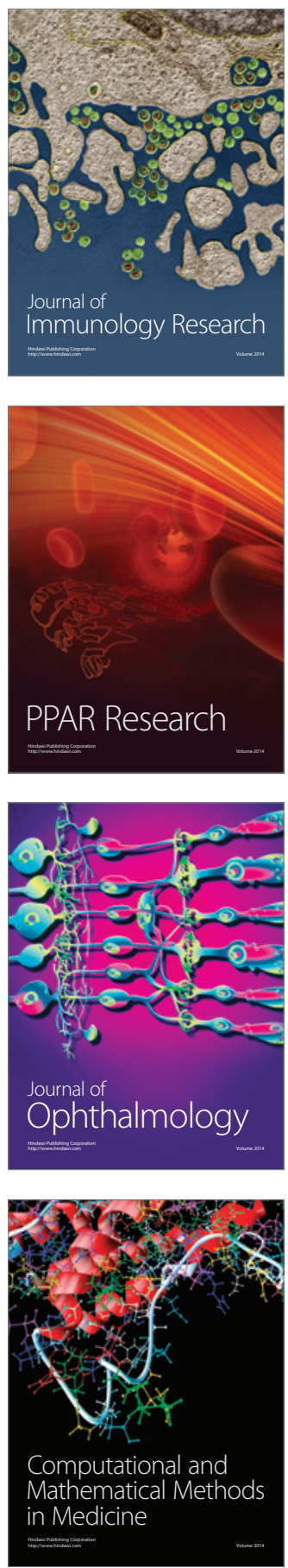

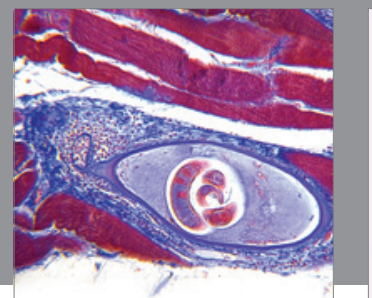

Gastroenterology

Research and Practice
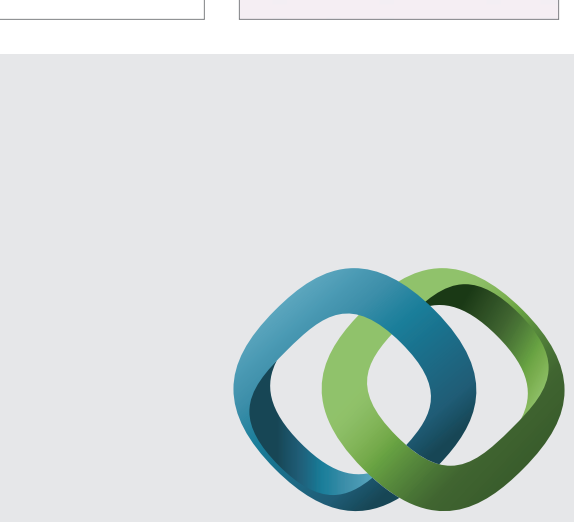

\section{Hindawi}

Submit your manuscripts at

http://www.hindawi.com
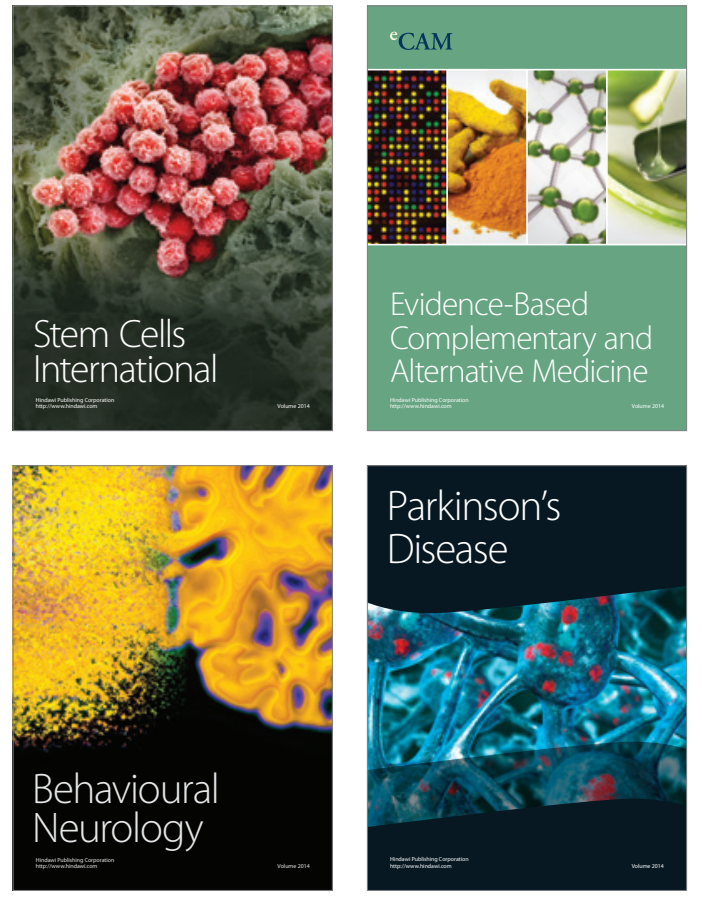
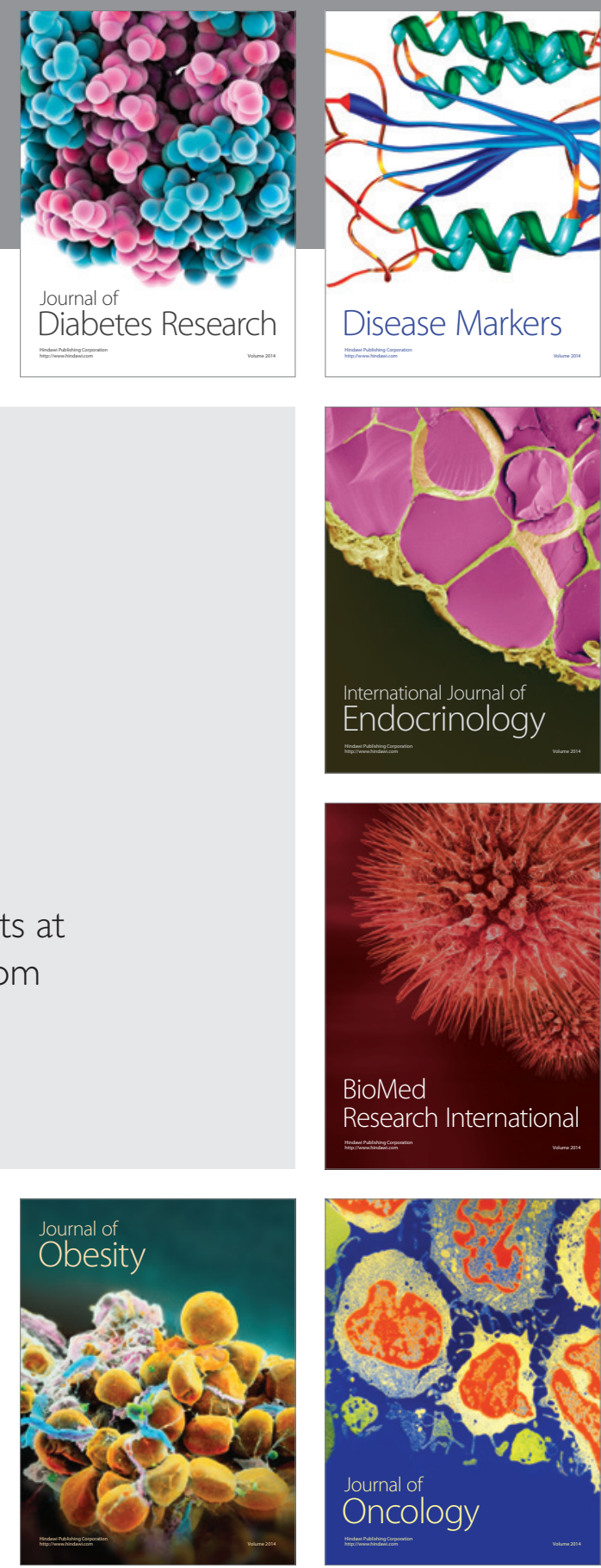

Disease Markers
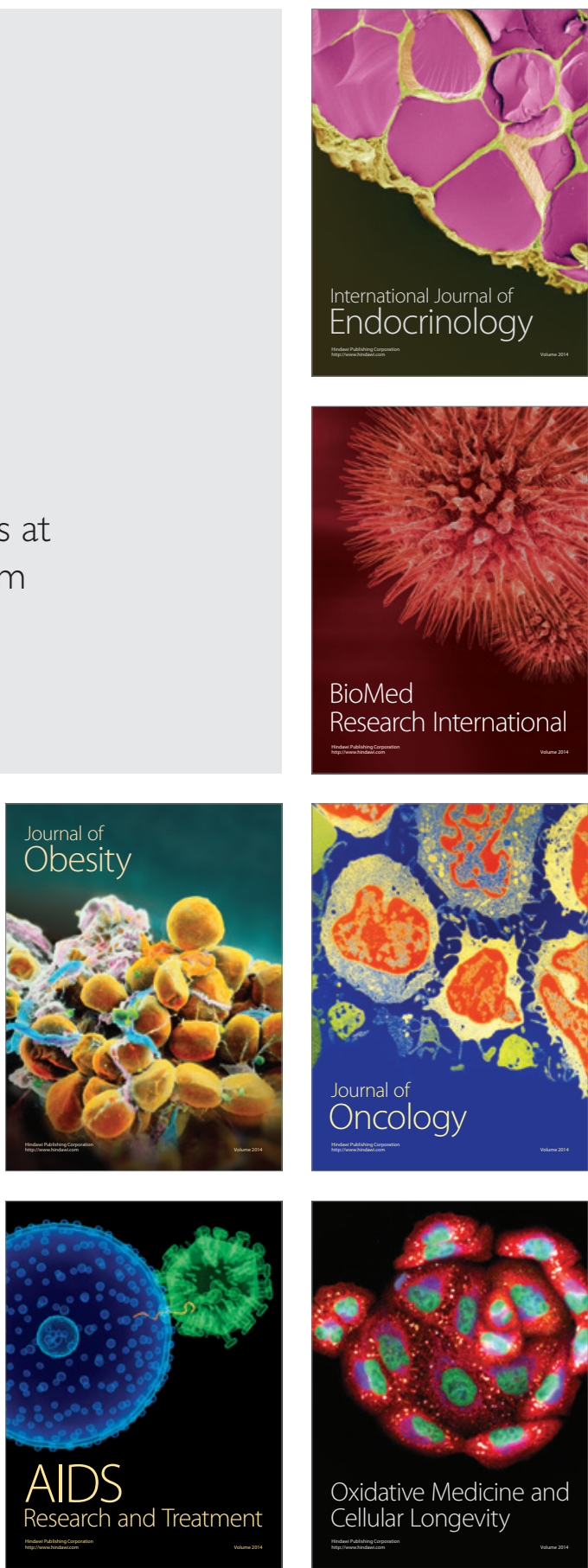